\title{
Optimizing Assignment of Tomahawk Cruise Missile Missions to Firing Units
}

\author{
Alexandra M. Newman, ${ }^{1}$ Richard E. Rosenthal, ${ }^{2}$ Javier Salmerón, ${ }^{2}$ Gerald G. Brown, ${ }^{2 *}$ Wilson Price, ${ }^{2}$ \\ Anton Rowe, ${ }^{2}$ Charles F. Fennemore, ${ }^{3}$ Robert L. Taft ${ }^{3}$ \\ ${ }^{1}$ Division of Economics and Business, Colorado School of Mines, Golden, Colorado 80401 \\ ${ }^{2}$ Operations Research Department, Naval Postgraduate School, Monterey, California 93943 \\ ${ }^{3}$ Naval Surface Warfare Center, Dahlgren, Virginia 22448
}

Received 12 September 2008; revised 6 July 2009; accepted 4 August 2009

DOI 10.1002/nav.20377

Published online 6 October 2009 in Wiley Online Library (wileyonlinelibrary.com).

\begin{abstract}
The Tomahawk land-attack cruise missile can be launched from a ship or submarine, and can deliver its warhead precisely to a target at long range. There are several variants of the Tomahawk missile, each with specialized capabilities. For each Tomahawk Missile Sequence Number (MSN) task (i.e., mission), the Tomahawk missile variants can be ranked with respect to their ability and cost effectiveness to perform that task. A given land attack strike order may involve a large number of Tomahawk missiles and numerous Tomahawk launch platforms. Operational planners select, in real time, feasible launch platforms to execute Tomahawk taskings. The Tomahawk tasking in a strike order includes not only primary assignments but also backup assignments. On board each launch platform, the precise allocation of specific Tomahawk missiles to the Tomahawk MSN task assigned is optimized with a model described here. We help naval operational planners select, in real time, appropriate feasible launch platforms to fulfill the Tomahawk tasking in a strike order. (C) 2009 Wiley Periodicals, Inc. Naval Research Logistics 58: 281-295, 2011
\end{abstract}

Keywords: weapon-target assignment; Tomahawk; multi-objective optimization; integer programming; operations research; military operations research

"Be swift like lightning in the execution;

And let thy blows, doubly redoubled,

Fall like amazing thunder on the casque

Of thy adverse pernicious enemy"

Richard II, Shakespeare

\section{INTRODUCTION}

The Tomahawk (Fig. 1) is a long-range, subsonic, landattack missile manufactured by Raytheon. It is a tactical, conventional weapon that can be launched from U.S. Navy surface ships and submarines, and some Royal Navy submarines. It flies a planned route, delivering its warhead precisely to a target at long range, at a specified time. A given land attack strike order may involve a large number of Tomahawk missiles of different types (called Tomahawk variants) and numerous Tomahawk launch platforms.

In this article, we describe a "predesignation" optimization model and a fast heuristic algorithm to help the U.S. Navy's

*Correspondence to: G.G. Brown (gbrown@nps.navy.mil) operational planners select, in real time, feasible launch platforms to fulfill the tasking in a strike order. Predesignation is the process by which a set of one or more specific Tomahawk missiles, on one or more specific firing platforms is matched to the mission requirements in a "strike plan." For a given target (that is, a set of aim points to be attacked in a single, coordinated action), a strike plan specifies how many and what kind of Tomahawk missiles are requested. In addition, we address specific aspects of a goal hierarchy involved in the coordination of a large number of Tomahawk missiles and naval platforms.

There is a rich and long-standing literature on missile assignment. For example, the early work of Bracken and McCormick [4] presents a nonlinear approximation to a weapon allocation problem where the goal is to maximize expected inflicted damage. Matlin [26] reviews much of the early work, which is aligned with the Tomahawk-to-task allocation carried out by the Tactical Tomahawk Weapon Control System (TTWCS) Urioste [34].

Weapon assignment is part of a large class of optimization models known as resource allocation problems. Jaiswal [19, pp. 132-137, and references therein] divides the 


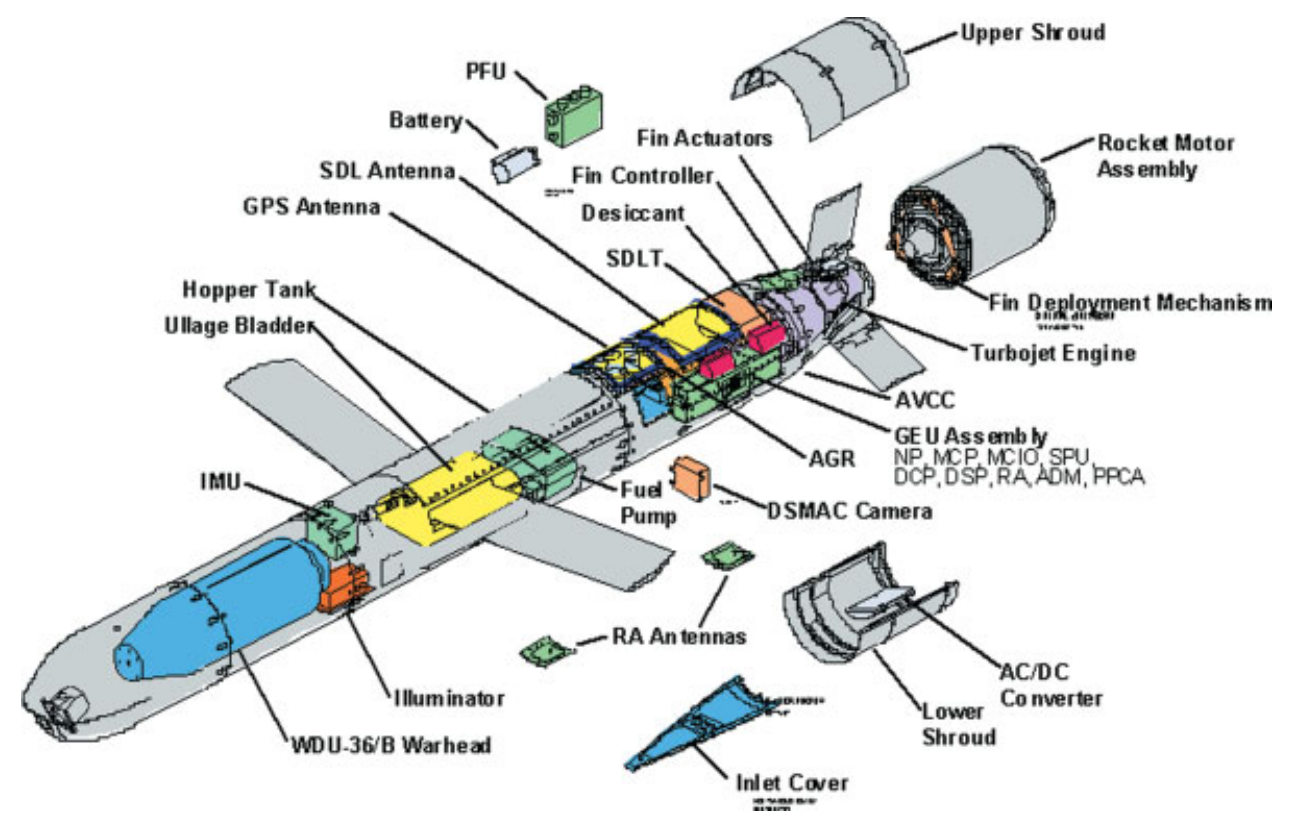

Figure 1. Tactical Tomahawk Missile. [Source: Naval Surface Warfare Center, Dahlgren Division, 2003].

complex decision process of planning these missions into three hierarchically structured classes: (a) weapon mix problems, which determine the acquisition of a weapons mix that inflicts maximum damage to a set of targets, subject to constraints including cost, manpower, and weapon availability; (b) weapon deployment problems, which assume a given weapon mix and candidate locations where these weapons can be deployed, and which seek a weapon deployment to maximize damage on a given set of targets; and (c) the weapon-to-target allocation problem, which is "Given the mix of weapons deployed at specified locations, determine the allocation of weapons to each target to inflict desired damage." The resource allocation concepts from our literature review have been modified, abstracted, and extended in order to conform to the task-to-firing unit allocation addressed in this article.

\section{THE TOMAHAWK MISSILE AND ITS TACTICAL USE}

The Tomahawk entered service in 1983, and first saw combat in the 1990-1991 Gulf War. Tomahawks are now available in a number of variants, differing in the type of munitions carried, guidance system, and other features. Newer versions have improved satellite communications that allow reprogramming the missile while in flight, faster launch times, and the ability to loiter in an area of emerging targets. Tomahawks use both inertial and GPS navigation systems, as well as terrain contour matching radar guidance [13] that compares a stored map reference with the actual terrain to determine the missile's position. A digital optical system that compares a stored image of the target with the observed target provides guidance in the terminal target area.

The Tomahawk has proven to be a remarkably flexible weapon. In 1991, hundreds of Tomahawks were launched against land targets in Iraq during Operation Desert Storm, principally to attack the Iraqi air defense network. In September 1995, USS Normandy (CG 60) fired 13 Tomahawks against Bosnian Serb targets, contributing to the subsequent cease-fire in Bosnia [3]. Tomahawks were used again in 1996 during Operation Desert Strike (Fig. 2).

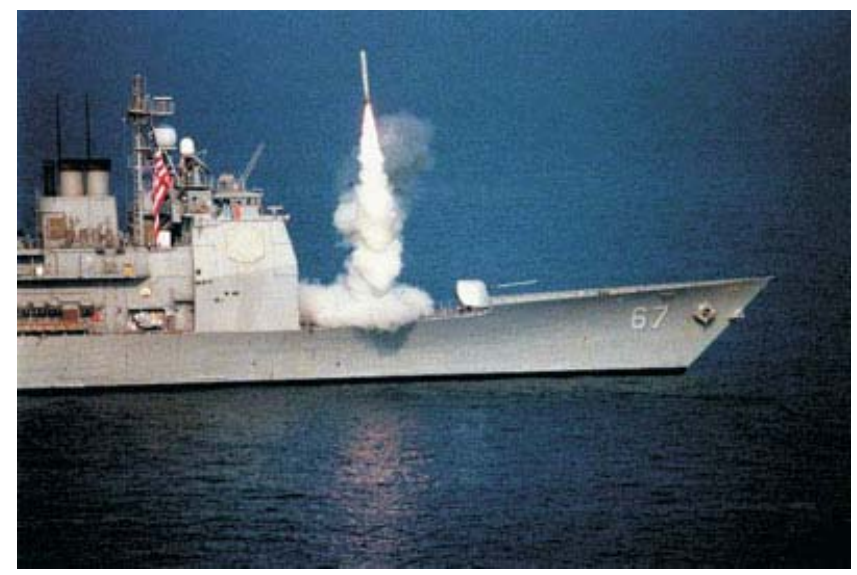

Figure 2. Flying her battle flag, USS Shiloh (CG-67) fires a Tomahawk land attack missile in Operation Desert Strike, 3 September 1996. 
Initial loadouts on two AEGIS VLS half-modules

\begin{tabular}{|c|c|c|c|c|}
\hline Destroyer & $T_{1}$ & $T_{1}$ & $T_{2}$ & $T_{3}$ \\
\hline Cruiser & $T_{1}$ & $T_{2}$ & $T_{2}$ & $T_{3}$ \\
\hline
\end{tabular}

Loadouts after manual allocation
\begin{tabular}{|c|c|c|c|c|}
\hline Destroyer & $T_{1}$ & $T_{1}$ & & $T_{3}$ \\
\hline Cruiser & & $T_{2}$ & $T_{2}$ & $T_{3}$ \\
\hline
\end{tabular}

Loadouts after optimal allocation
\begin{tabular}{|c|c|c|c|c|}
\hline Destroyer & & $T 1$ & $T 2$ & $T_{3}$ \\
\hline Cruiser & $T 1$ & & $T 2$ & $T 3$ \\
\hline
\end{tabular}

Figure 3. Impact of a Tomahawk missile sequence number task-to-firing unit allocation on subsequent strike plan capability.

Equipping submarines with the highly accurate Tomahawk adds a new conventional land attack strike warfare capability. The employment of Tomahawks enables surface ships and submarines to hit a myriad of key targets such as command centers, fortified positions, and airfields.

Before leaving port, naval ships and submarines (referred to as the "firing units" in this article) are loaded with Tomahawk missiles. The fleet command determines the number of Tomahawks and the specific variants loaded on a firing unit. The weapon station's (port facility) and firing unit's commander decide where each specific Tomahawk is loaded in the launcher or torpedo room. For AEGIS cruisers and destroyers [20], the Naval Surface Warfare Center Port Hueneme Division designed and maintains a computer program that suggests the exact Tomahawk loadout positions. The program takes into account the capabilities and limitations of the vertical launch system (VLS) on the AEGIS ships.

A Tomahawk Missile Sequence Number (MSN) task-tofiring unit allocation is decided at the fleet command level. This allocates each Tomahawk MSN task in a strike plan to a particular firing unit; a missile-to-Tomahawk MSN task allocation on a firing unit is assigned by Tactical Tomahawk Weapons Control System on each firing unit. This allocates a specific Tomahawk loaded on the firing unit to each particular Tomahawk MSN task assigned to that firing unit; this capability has been documented in a number of Naval Surface Warfare Center Dahlgren Division (NSWCDD) [27] technical reports (see, e.g., Refs. 1,14 and 15) and is not discussed further in this article.

For a given set of Tomahawk MSN tasks in a strike plan, a Tomahawk Strike Coordinator (TSC), usually a Lieutenant Commander or Commander, develops one, or more, Tomahawk MSN task-to-firing unit allocation alternatives and presents these to the fleet command for approval. The TSC must consider and balance many factors in building a strike plan. These include geographical (e.g., distance to targets from available firing units, aim points, flight route coordination), logistical (e.g., inventory of missiles available, technical conflicts with other missiles, preparation time, required time on target), and operational (e.g., need for redundancy in case of failure) factors. Simultaneously, the TSC must consider many potentially conflicting objectives and preferences, such as [7]:

- Allocating tasks to firing units so that each firing unit has a Tomahawk variant that can perform the task allocated in a cost-effective manner. For example, if the target can be struck by a Tomahawk variant with terrain contour matching radar guidance capability, we prefer not to launch an "overqualified" variant which also has GPS navigation capability.

- Leaving each firing unit with a sufficiently large residual strike capacity, both individually and as part of a battle group, so that it continues to be effective as a naval force after expending the assigned missiles. Firing unit assignments allocate missiles to existing targets while platform residual capacity preserves the ability to address potential targets (as exemplified in the example following this bulleted list).

- Expending missiles first from firing units that will soon depart the theater of operations, and avoiding assignments that interfere with firing units engaged in other duties.

The TSC has a very difficult job that must often be performed under great time pressure, and in conjunction with other duties. As an illustration of the complexity of the problem, consider a simple example in which there are only two firing units in a naval strike force: an AEGIS destroyer and an AEGIS cruiser. On both AEGIS platforms, missiles are carried in VLS modules that can contain eight cells, each of which can hold a Tomahawk. Each module is divided into two half-modules of four cells. At most one Tomahawk can be powered up at a time in a VLS half-module. For this example, Fig. 3 shows the impact of a Tomahawk missile sequence number task-to-firing unit allocation on subsequent strike plan capability. The upper part of the figure shows hypothetical initial loadouts in a VLS half-module on the AEGIS destroyer and an AEGIS cruiser. The AEGIS destroyer is loaded with four Tomahawks in a single half-module of the firing unit's VLS (and no other Tomahawks). Specifically, there are two variant $T 1$ Tomahawks, one variant $T 2$ Tomahawk, and one T3 in the half-module. The AEGIS cruiser 
is loaded with four Tomahawks in a single half-module of the firing unit's VLS (and no other Tomahawks). There is one variant $T 1$ Tomahawk, two $T 2 \mathrm{~s}$, and one $T 3$ in the half-module.

The TSC creates a strike plan that has two MSN tasks. The first MSN task (MSN 1) requires the launch of a single missile, and can be performed by either a Tomahawk variant $T 1$ or a Tomahawk variant $T 2$; but, it is more cost effective to use a $T 2$ because the $T 1$ has all the capabilities of a $T 2$ as well as additional capabilities that are not needed to perform MSN 1. Thus, using an overqualified $T 1$ would waste capability and might degrade the readiness of the force to launch future strikes.

The Tomahawk selected to perform MSN 1 must be powered up and launched at the same time as the Tomahawk launch time for the other MSN task (MSN 2). This second task requires the launch of a single Tomahawk variant $T 1$. Because both MSN tasks have the same missile launch time, they conflict, and may not be launched from the same platform. Therefore, one task must be allocated to the AEGIS destroyer, and one task to the AEGIS cruiser.

Suppose we assign MSN 1 to the AEGIS destroyer and MSN 2 to the AEGIS cruiser. Then, onboard the AEGIS destroyer, the Tactical Tomahawk Weapon Control System (TTWCS) missile-to-Tomahawk MSN task allocation would assign the Tomahawk variant T2 to MSN 1 in order to maximize the future launch capability of the AEGIS destroyer. Onboard the AEGIS cruiser, the Tomahawk variant $T 1$ would be assigned to MSN 2 because it is the only Tomahawk missile that can perform the task. Notice that as a result of this allocation it would not be possible to perform a subsequent strike plan requiring two $T 1$ s to be launched at the same time, nor a strike plan that might be performed by launching two, more cost-effective, $T 2 \mathrm{~s}$ at the same time.

However, if we allocate MSN 1 to the AEGIS cruiser, and MSN 2 to the AEGIS destroyer, then onboard the AEGIS destroyer the TTWCS missile-to-Tomahawk MSN task allocation would assign a $T 1$ to MSN 2; and, onboard the AEGIS cruiser a T2 would be assigned to MSN 1 because the Tomahawk variant $T 2$ is more cost-effective to use than the Tomahawk variant $T 1$. Notice that the result of this allocation allows us to execute a subsequent strike plan that requires two Tomahawk variant $T 1$ s to be launched at the same time, or a subsequent strike plan in which two more cost-effective missiles can be launched at the same time.

While it might be easy to find the preferred Tomahawk MSN task-to-firing unit allocation in this simple example by inspection, this is too complex to do when multiple Tomahawk MSN tasks with conflicting times need to be allocated to multiple firing units in a naval strike force. As indicated in the example above, the missile-to-Tomahawk MSN task allocation capabilities that were (a) initially implemented by
Naval Surface Warfare Center, Port Hueneme Division, as a stand-alone capability, (b) subsequently implemented by NSWCDD within TTWCS, and (c) later formulated independently by Kuykendall [25], all reflect that the missile-to-task allocation on board a firing unit has to be performed in a manner that maximizes future launch capability of the firing unit.

\section{PROBLEM DEFINITION}

We first provide some definitions and rules needed to define the problem and formulate a model.

\subsection{Conflicting Tasks}

Two Tomahawk MSN tasks are said to be in conflict if the preparation and launch time epochs for each missile allocated to perform the Tomahawk MSN tasks overlap. Time conflict task sets are constructed based on the preparation and launch time epochs of the Tomahawk MSN tasks, and the various firing unit capabilities and restrictions. A Tomahawk MSN task may be in more than one time conflict task set. Constraints are generated to reflect each firing unit's capability to handle tasks with conflicting times.

\subsection{Firing Unit Characteristics}

There are several types of surface ship and submarine firing units. Each type of firing unit has particular weapons storage and launch characteristics that impose different constraints. The surface ships store their Tomahawks in VLSs. Each ship may hold a different number of missiles, and the cell-location of the missiles may differ from ship to ship. Depending on the class of submarine, Tomahawks can be stored in the torpedo room or in a vertical launch canister, with capacity varying by submarine class.

Allocating a Tomahawk MSN task to a firing unit that is already engaged in some other activity incurs a so-called employment penalty; thus, an otherwise engaged firing unit is used to perform such a task only if necessary.

Each firing unit is characterized as either an expend or a non-expend unit. A firing unit might be designated as expend if it is scheduled to leave the theater of operations soon, and thus it is advantageous to the remaining force in theater if the departing firing unit launches its weapons. For non-expend firing units, we allocate Tomahawk MSN tasks to maximize the ability to perform follow-on strikes.

\subsection{Tasks and Task-Parts}

A Tomahawk MSN "task" is made up of one or more missiles that are to be prepared for launch to fly a particular over-land route and attack a specified aimpoint. A task 
can have one or more task-parts (defined below), each of which requires at least one missile. "Strike packages" are sets of tasks or missions created by the TSC. For example, a strike package may contain the following information: "Task 1 , requires one primary part, one ready-spare part, and one backup part, Tomahawk variant $T 1$, with earliest/latest time to launch 00:35/00:40; Task 2, requires one primary part and one backup part, Tomahawk variant $T 2$, with earliest/latest time to launch 00:37/00:42; etc." After the strike packages are created, the TSC sends them (via the designated communication system) to the firing units. The firing units return exception reports detailing missions they cannot complete as specified. Note that in our system, the allocation of successive strike packages is dynamically incorporated into the optimization. That is, the execution sequence freezes the assets selected for previous allocations and proceeds with subsequent packages from the remaining assets.

There are five types of task-parts:

- A primary task-part requires one or more primary missiles that are to be launched to fly a particular over-land route and are to attack a specified aimpoint.

- A ready-spare task-part is associated with a specific primary task-part, and requires one or more readyspare missiles (located on the same firing units as the task's primary missiles). The ready-spare missiles provide redundancy for the primary missiles, in case some of the primary missiles do not launch successfully.

- A backup task-part is associated with a specific primary task-part, and requires one or more backup missiles located on firing units other than those that have the task's primary missiles. The backup missiles provide a second-level redundancy for the primary missiles, in case the required total number of primary and ready-spare missiles is not launched successfully from primary firing units.

For completeness, we describe two other types of taskparts that are set aside at the outset, that is, they are not available in the allocation problem modeled in this article.

- A call-for-fire task-part requires one or more missiles be reserved for launching in support of friendly force shore operations during a specified time interval.

- A pooled task-part designates one or more missiles to be ready to be used in support of last-minute tasks during a specified time interval. If a last-minute need arises for a firing unit with pooled missiles to perform a specific primary task, then the appropriate number of pooled missiles can be selected for launch from the firing unit to attack the specified aimpoint.
A number of constraints guide the assignment of taskparts:

- Tasks are classified as separable or nonseparable: if a task is separable (nonseparable) then all the missile requirements of a task-part associated with the task can (cannot) be allocated to different firing units.

- Some firing units are designated as spread, and, if possible, the primary and back-up task-part assignments should be allocated among as many of these firing units as possible. Note: A related concept is known as "task-part spreading." For example, a primary taskpart that is designated as spread should be allocated among different firing units. This article incorporates spread firing units, but not spread task-parts.

- A ready-spare task-part must be assigned to a firing unit that is assigned an associated primary task-part. Also, in the allocation of ready-spare and primary task-parts for a specific separable task, for each firing unit, the required number of ready-spare missiles needed for the ready-spare task-part should be no more than the number of primary missiles needed for the primary task-part.

- A backup task-part must not be assigned to a firing unit that is assigned an associated primary task-part. Some firing units, especially submarines, may be excluded from being assigned backup task-parts by the TSC.

- A task is considered "allocated" only when all the missiles required for each of its task-parts have been assigned. Partial allocation of a task is not allowed in practice and our formulation explicitly avoids that possibility.

\subsection{Launch Areas}

Each firing unit is located in a specific launch area, and can only be assigned to strike targets that are geographically feasible from that area. Relocation of the firing unit to a different launch area is beyond our planning scope, and is not considered.

\subsection{Missile-to-Mission Matching}

There are multiple Tomahawk missile variants, and each one is designated by its Expanded Missile Identification (XMID). For the missile-to-task allocation that takes place on the individual firing units, the Tomahawks that are capable of performing each task are identified, prioritized, and allocated based on a number of factors. Although the TSC does not have information concerning all of the factors, he has knowledge concerning the Tomahawk missile loadout on each firing unit, and the cost effectiveness of using a particular Tomahawk variant (i.e., XMID) to perform a task. For any 
task, a Missile Mission Matching (or $\mathrm{M}^{3}$ ) list of XMIDs that are able to perform the task is constructed and prioritized from the most to the least cost-effective Tomahawk variant to perform the task. The task-to-firing unit allocation should assign task-parts to firing units in order to maximize the potential follow-on launch capability of the force by allowing the firing units to perform Tomahawk-to-task allocations that use the most cost effective Tomahawks.

\subsection{Tomahawk Strike Coordinator Overrides}

While our intent here is to develop an automated decision aid to allocate task-parts to firing units, there are cases in which the suggested allocation should not be applied and other cases in which the TSC may wish to override the task part to firing unit allocation, e.g.:

- Tasks can be divided into two groups: execute tasks and launch-plan tasks. "Execute" tasks are tasks whose parts have already been allocated to firing units, and the firing units' commanders have confirmed that Tomahawks can be allocated to the task parts. Within the automated decision aid to allocate task-parts to firing units, any prior execute task allocations to firing units should be accounted for, but not changed. "Launch-plan" tasks are those whose task parts have not yet been allocated to firing units. The job of the automated decision aid is to allocate launch-plan task-parts to firing units, while taking prior execute tasking into account.

- The TSC can allocate a particular task-part, or a portion of a task-part, to a specific firing unit, or even designate launch of a specific missile. Such general, ad hoc constraints offering the TSC complete control over predesignation are a key to gaining and keeping the confidence and trust of the TSC. In our experience, planners distrust "black box" tools over which they have no control, and find ways to avoid using such tools.

\section{MATHEMATICAL MODELING}

\subsection{Objective Functions}

We have developed objective functions by interviewing TSCs, their commanding officers and senior naval officials. The objective functions listed below are for a streamlined model formulation presented in the sections that follow that deals only with the allocation of Tomahawk tasks to AEGIS ships. The notation is defined in detail in the Appendix, but the definitions of various terms are repeated here.

OBJECTIVE 1 (Number of unassigned task-parts; to be minimized): This objective expresses the number of taskparts not allocated to firing units. While partial allocation of a task is not allowed, this objective could be modified to reflect the importance and relative priority of the various tasks and task-parts.

$$
\text { Objective } k=1: \quad \min z_{1} \equiv \sum_{\substack{t \in T, p \in P, m \in M_{t p}}} U_{t p m},
$$

where $U_{t p m}$ equals 1 if the $m$-th missile requirement for task-part $p$ in task $t$ is unmet, and 0 otherwise.

OBJECTIVE 2 (Use of firing units currently engaged in other tasking; to be minimized): This objective penalizes distraction of firing units engaged in other missions.

$$
\text { Objective } k=2: \quad \min z_{2} \equiv \sum_{s \in S} p_{s} V_{s},
$$

where $V_{s}$ equals 1 if ship $s$ is used, and 0 otherwise and where $p_{s}$ is the penalty for using ship $s$.

OBJECTIVE 3 (Number of primary task-parts allocated to designated "expend" firing units; to be maximized): This objective rewards firing units regarded as "expend" if they are assigned primary task-parts (not redundancies).

$$
\text { Objective } k=3: \quad \max z_{3} \equiv \sum_{\substack{t \in T, s \in S_{t} \cap S^{E}, p \in P, m \in M_{t p}}} Y_{s t p m}
$$

where $Y_{\text {stpm }}$ equals 1 if ship $s$ is assigned to perform the $m$-th missile requirement for task-part $p$ in task $\mathrm{t}$, and 0 otherwise.

OBJECTIVE 4 (Deviations in residual missile inventory across firing units; to be minimized): This objective seeks to level residual missile inventories across firing units (except for expend ships) after primary task-parts are assigned. The rationale for this objective is to avoid weakening non-expend ships for potential future engagements.

$$
\text { Objective } k=4: \quad \min z_{4} \equiv \sum_{s \in S \backslash S^{E}} \mathrm{RD}_{s},
$$

where $\mathrm{RD}_{s}$ is the difference between the residual number of missiles on ship $s$ and the average residual number of missiles across all "non-expend" ships.

OBJECTIVE 5 (Number of "spread" firing units used for primary task-part assignments; to be maximized): This objective counts the number of firing units included in our predesignation. Maximizing this number spreads the allocation of primary task-parts, minimizes the impact of losing one or several ships, and encourages participation by many 
firing units. Some ships can be marked to be "preferred" for primary task-parts by the TSC.

$$
\text { Objective } k=5: \quad \max z_{5} \equiv \sum_{s \in S^{\mathrm{PR}}} \mathrm{PR}_{s},
$$

where $\mathrm{PR}_{s}$ equals 1 if any primary task-part is allocated to ship $s$ (only for $s \in S^{\mathrm{PR}}$ ), and 0 otherwise. $S^{\mathrm{PR}} \subseteq S$ is a subset of AEGIS ship firing units to which we wish to allocate primary task-parts.

OBJECTIVE 6 (Number of "spread" firing units used for backup task-part assignments; to be maximized): This objective is the same as Objective 5, but applies to backup task-parts.

$$
\text { Objective } k=6: \quad \max z_{6} \equiv \sum_{s \in S^{\mathrm{BU}}} \mathrm{BU}_{s},
$$

where $\mathrm{BU}_{s}$ equals 1 if any back-up task-part is allocated to ship $s$ (only for $s \in S^{\mathrm{BU}}$ ), and 0 otherwise. $S^{\mathrm{BU}} \subseteq S$ is a subset of AEGIS ship firing units to which we wish to allocate backup task-parts.

OBJECTIVE 7 (Use of non-cost-effective missiles; to be minimized): This objective assesses the cost effectiveness of the missiles that may be allocated to tasks on the firing units, and minimizing the use of non-cost-effective missiles preserves potential follow-on launch capability.

$$
\text { Objective } k=7: \min z_{7} \equiv \sum_{\substack{t \in T, s \in S_{t}, h \in H_{s}, w \in W_{s h}, p \in P, m \in M_{t p}}} m_{t w p}^{3} X_{\text {shwtpm }},
$$

where $m_{t w p}^{3}$, is the penalty for allocating weapon $w$ to part $p$ in task $t$ (based on $\mathrm{M}^{3}$ position of weapon $w$ for task $t$, and the weight of part $p$ to match the $\mathrm{M}^{3}$ list). Also, $X_{\text {shwtpm }}$ equals 1 if ship $s$ is assigned to perform the $m$-th missile requirement for task-part $p$ in task $t$ (tentatively using a weapon of type $w$ in half-module $h$ ), and 0 otherwise.

OBJECTIVE 8 (Relative value of residual salvo; to be maximized): This objective assesses the potential missile loadout on the firing units after Tomahawks are launched to perform primary task parts, in order to maximize the potential follow-on salvo, that is, launch capability. (The formulation presented below only considers the "most valuable" missile type in a launcher half module. The objective can be modified to reflect all the missile types in a launcher half module.)

$$
\text { Objective } k=8: \quad \max z_{8} \equiv \sum_{s \in S, h \in H_{s}, w \in W_{s h}} v_{w} D_{s h w},
$$

where $v_{w}$ is the relative value of weapon $w$ for residual salvo computation.
Also, if based on the information held by the TSC, one or more weapons of type $w$ would remain on ship $s$ in halfmodule $h$ after firing all primary task-part missiles, at most 1 $D_{s h w}$ for that $(s, h)$ is allowed to be equal to 1 , and must be 0 otherwise.

\subsection{Model Formulation}

We present a simplified model formulation that covers most problem features. In this streamlined formulation, we have suppressed geographic proximity, substituting instead lists of geographically feasible assignments. Here, we consider only AEGIS ships as firing units. For details on modeling with SSN submarines, see Ref. 9. For details on SSGN modeling, see Ref. 8. The inclusion of submarines does not affect the solvability of the problem any more than adding new surface ships. Zumwalt-class ships [33] have not yet been inserted in the formulation. (For specifications of various combatant ship classes, see Ref. 21.) Only primary, readyspare, and backup task-parts are discussed in the following formulation. A structured list of variable and parameter definitions and a formal definition of constraints are provided in the Appendix.

\subsection{Solving the Multiobjective Optimization Problem}

The model that we have described is a mixed-integer linear program with multiple objective functions. In general, a multiobjective optimization problem may be written as (e.g., Ref. 11, p. 16):

$$
\begin{aligned}
\text { "minimize" } & F\left[z_{1}(x), z_{2}(x), \ldots, z_{|K|}(x)\right] \\
& \text { subject to } x \in \theta
\end{aligned}
$$

where $x=\left\{x_{1}, x_{2}, \ldots, x_{n}\right\}$ is a vector of decision variables, and $z_{1}, \ldots, z_{|K|}$ are objective functions of these decision variables, $\theta$ is the set of feasible decisions allowed by the constraints, and $F$ is some vector or scalar function of the objective function values. By necessity, the term "minimize" may have several meanings and the choice among them is subjective. If there is a value of $x$ that simultaneously optimizes each $z_{k}(x)$, then the multiobjective problem would be clear and simple, but such an ideal solution cannot be guaranteed, and is rare in practice.

For convenience, we assume that any objective that is to be maximized in the original formulation is redefined as its negation, so that all objectives are to be minimized.

\subsubsection{The Value Function}

If $F$ is a well-defined, scalar-valued function that all interested parties agree is an accurate representation of their preferences and priorities, then the multiobjective problem 
reduces to single-objective optimization, for which standard methods can be employed. Such $F$ functions are called value functions in a deterministic setting (which is the case here) or they are called utility functions in a stochastic setting. (See Keeney and Raiffa [22, pp. 82-116 and 131-218, respectively] for development of these functions and Harrison and Rosenthal [16] for their use in optimization models.)

\subsubsection{Linear Value Function}

The most commonly used value function is a weighted sum of the objective functions that has the advantage of being intuitively appealing to many people. This also has well-documented drawbacks. The problem becomes intractable if a nonlinear weighting is used. Despite its potential weakness, a linear value function (that is, weighted sums) is widely used and is often an advisable approach, especially when under time pressure. There is no way to avoid some subjective judgment on empirical observations of preliminary results when setting the weights. We look at the need for subjective judgment in multiobjective optimization (and other areas of OR) as an important distinguishing feature of OR versus, say, physics, because "we are engaged in the modeling of systems that involve people, not particles."

The formulation of the linear-value-function or weightedsum is:

$$
\begin{gathered}
(\mathrm{W}): z_{o}^{*}=\min z_{o}=\sum_{k \in K} \omega_{k} z_{k}(x) \\
\text { s.t. } x \in \theta
\end{gathered}
$$

where $\omega_{k}>0$ is the weight given to objective $k$.

\subsubsection{Pareto Optimality}

For a multiobjective problem, it is always preferred to choose a Pareto-optimal solution (e.g., Ref. [11], p. 24), that is, one from which it is impossible to find another point that improves the attainment of some objective(s) without simultaneously diminishing the attainment of some other objective. There are usually many Pareto-optimal points, perhaps an infinite number. Where $|K|=2$, the Pareto-optimal set is a curve, the efficient frontier, which is easy to generate and extremely useful for presenting alternatives to decision makers. The case of $|K|>2$ is more difficult and has been treated by Zeleny [37], Rosenthal [28], Steuer [31], and White [35]. One fortunate result in the theory of multiobjective optimization is Soland's Theorem [30], from which it follows that solving problem (W) yields a Pareto-optimal solution, although not all efficient points may be derived as the solution to a problem like $(\mathrm{W})$.

\footnotetext{
${ }^{1}$ This observation is classic Rick Rosenthal.
}

\subsubsection{Hierarchical Optimization}

Another intuitively simple idea is prioritizing the multiple objective functions and then optimizing them, one at a time, in priority order. Attainment of optimal (or near-optimal) values of higher priority objectives becomes a constraint when optimizing the lower priority ones. This method requires solving the following sequence of increasingly restricted single-objective problems $\left(\mathrm{H}_{k}\right)$, for $k=1, \ldots,|K|$ :

$$
\begin{aligned}
\left(\mathrm{H}_{k}\right): z_{k}^{*}=\min & z_{k}(x) \\
\text { s.t. } & x \in \theta \\
& z_{k^{\prime}}(x)=z_{k^{\prime}}^{*}, \forall k^{\prime}<k
\end{aligned}
$$

One weakness of this hierarchical optimization (also known as pre-emptive priorities) is that the optimization at each step depends upon the existence of multiple optima in the previous step. Without multiple optima in step $k$, the method converges before considering objectives $k+1, \ldots,|K|$. Another valid criticism of hierarchical optimization is that it may bar consideration of some sensible opportunities to trade off a small decrement in a high-priority objective in return for a large improvement in a low-priority one. These issues can be addressed by relaxing the higher-priority objective's aspirations, replacing each equality constraint in $\mathrm{H}_{k}$ by an inequality bounded by some given fraction of the optimal value $z_{k}^{*}$.

If the weights are chosen such that $\omega_{1}>>\omega_{2}>>\cdots>>$ $\omega_{|K|}$, then the weighted-sum objective yields the same solution as hierarchical optimization. In practice, a large disparity in the magnitude of the weights and objective coefficients can be computationally problematic. This is because in order for the low-priority objectives' weights to have any influence on the solution, the optimality tolerance needs to be set very close to zero, which in turn may cause the lowerpriority objectives' contributions to the value function to be ignored by the optimization numerics. Normalization and scaling across all objectives should be implemented to help reduce this risk.

The $(\mathrm{W})$ and $(\mathrm{H})$ formulations above can be solved as presented, or approximated by a problem cascade approach, as in Brown et al. [6, p. 341]. This strategy is also known as fix-and-relax $[10,12]$. This technique relaxes the integrality of most of the decision variables to make the problem easier. For example, only those variables related to a subset of tasks are forced to assume integer values. Then, these variable values are fixed and a new subset of variable values is forced to be integral, until all of them are fixed. Algorithmic details are provided by Demir [9]. We find this approach may help reduce computational time for cases in which $(\mathrm{W})$ or $(\mathrm{H})$ take a long time to converge, without much degradation in the achieved objectives. However, it also increases the computational time in easier instances due to the multiple models 
that need to be solved. As our computational experiments are restricted by a short time limit, we do not discuss the cascade approach.

\subsubsection{Heuristic Optimization}

In addition to the conventional multiobjective optimization methods of solving $(\mathrm{W})$ and $\left(\mathrm{H}_{k}\right)$, we have also developed a specialized, custom heuristic for finding good solutions quickly. The heuristic uses sequential insertion: Queues of task-parts, firing units, and missiles are maintained, with priorities in the queues determined by a battery of problemspecific criteria. As assignments are made from the queues, the queues are replenished and reordered. Occasionally, we invoke a restart to give the heuristic an opportunity to improve the solution with large changes, rather than with small increments. Details of this heuristic appear in Salmeron [29] and Arnold [2], but initial steps in exploring heuristics for this problem are due to Kirk [23] and Hodge [17].

Over the period in which they have been involved in modeling Tomahawk missile assignment, the Naval Postgraduate School team of students and faculty has worked closely with experienced operations officers. This close contact with operational practice has allowed the team to gain domain-specific knowledge that allows the resolution of various modeling issues. For example, Kubu [24] systematically studies situations in which the heuristic is unable to assign all tasks to firing units. He introduces a diagnostic module that provides the TSC with likely reasons as to why a task cannot be covered. He also provides a prescriptive module for suggesting changes to the inputs so that all tasks can be allocated. Kubu collects domain-specific knowledge about our problem and assembles a catalog of suggested adjustments to diagnose and eliminate infeasibilities. The most effective tool is an adjustment of time windows performed by sliding the earliest or latest launch times in order to avoid task conflicts.

\section{TEST PROBLEMS AND COMPUTATIONAL EXPERIENCE}

\subsection{Test Problems}

We have developed a dataset of 35 test problems. We refer to the first 22 test problems as lab problems, and the other 13 as exercise problems. The lab problems are complete inventions [2], based upon war-fighter and engineering judgment, but without empirical basis. In contrast, the exercise problems are based entirely on carefully recorded observations of naval exercises at sea attended by Wingeart [36]. Wingeart collected both inputs and outputs of all the tasks to firing unit allocations completed in two major U.S. Navy Third Fleet exercises known as Rimpac and Texas-Thunder. His analysis
Table 1. Predesignation optimization problem characteristics for lab and fleet exercise test cases.

\begin{tabular}{lccr}
\hline Test cases & $\begin{array}{c}\text { No. of } \\
\text { firing units }\end{array}$ & $\begin{array}{c}\text { No. of } \\
\text { tasks }\end{array}$ & $\begin{array}{c}\text { No. of } \\
\text { tasks-parts }\end{array}$ \\
\hline 22 Lab problems [2] & $4-8$ & $13-26$ & $104-232$ \\
13 Exercise problems [36] & $4-8$ & $18-100$ & $28-128$ \\
\hline
\end{tabular}

includes comparisons of what would have happened had our model been used, versus the actual exercise results.

Our runs were made on a $2 \mathrm{GHz}$ laptop with $2 \mathrm{~GB}$ of RAM. Exact models $(\mathrm{H})$ and $(\mathrm{W})$ were implemented in GAMS [5] and solved with CPLEX 9.0 [18]. The heuristic was implemented in Java [32].

\subsection{Results for Lab Problems}

Table 1 shows problem characteristics for both lab [2] and Third Fleet exercises [36] test cases. Note that " $x-y$ " indicates a range from a minimum of $x$ to a maximum of $y$. Tables 2 and 3 show detailed results for the 22 lab problems and the 13 exercise problems, respectively.

By column, Table 2 shows the case name, the optimal solution to each of the eight goals, and the computational time for each of the three methods: Heuristic, (W) and (H) models, respectively. For all of these test cases, the exact optimization solutions (W) and (H) are identical. In some cases, the heuristic solution, which is displayed by an underlined alternative value, is of inferior quality. For example, all three methods achieve the same solutions for cases " 1 " and " $1 \mathrm{~A}$," but for case " $1 \mathrm{~B}$ " the heuristic solution is 3 for goal $k=6$, when the optimal objective should be 4 . Of course, the heuristic solution might be superior for goals $k+1, \ldots, 8$ (see, e.g., case "2") but that can only happen if it is of inferior quality for a hierarchically superior goal $k$. Overall, heuristic solutions are of acceptable quality. In the 22 lab problems, the heuristic never fails to optimize the first goal, only fails to optimize the second goal in one of the problems (case " 3 "), and the third goal in another problem (case " 6 "). Goal $k=4$, "leveling missiles left on firing units by minimizing absolute deviations" is apparently the most difficult goal, since the heuristic misses the optimal solution in 10 of the remaining lab cases. Indeed, most of the time consumed by the $(\mathrm{H})$ method in solving the eight problems $\left(\mathrm{H}_{k}\right), k=1, \ldots, 8$, is spent in solving $\left(\mathrm{H}_{4}\right)$.

\subsection{Results for Exercise Problems}

In Table 3, "R-S $n$ " denotes the $n$-th strike scenario for the Rimpac exercise, and "T-Sn-m" denotes the $m$-th salvo within the $n$-th strike scenario for the Texas exercise. (Rimpac strikes have one unique salvo each.) Strikes are planned independently in that they may involve different groups of 
Table 2. Result comparison for lab problems: Heuristic objective value (underlined, if different) and (W)-(H) identical objective values.

\begin{tabular}{|c|c|c|c|c|c|c|c|c|c|}
\hline \multirow[b]{2}{*}{$\begin{array}{l}\text { Test } \\
\text { case }\end{array}$} & \multicolumn{8}{|c|}{ Goals } & \multirow[b]{2}{*}{$\begin{array}{l}\text { Solution time } \\
\text { (s): Heuristic } \\
\text { (W),(H) }\end{array}$} \\
\hline & $\begin{array}{l}\text { \# } 1 \text { (Min): } \\
\text { Unassigned } \\
\text { task parts }\end{array}$ & $\begin{array}{l}\text { \# 2 (Min): } \\
\text { Penalty } \\
\text { firing units }\end{array}$ & $\begin{array}{c}\text { \# } 3 \text { (Max): } \\
\text { Expend } \\
\text { units }\end{array}$ & $\begin{array}{c}\text { \# } 4 \text { (Min): } \\
\text { Deviation } \\
\quad \text { level }\end{array}$ & $\begin{array}{c}\text { \# } 5 \text { (Max): } \\
\text { Spread } \\
\text { primary }\end{array}$ & $\begin{array}{c}\text { \# } 6 \text { (Max): } \\
\text { Spread } \\
\text { back-up }\end{array}$ & $\begin{array}{c}\text { \# } 7 \text { (Min): } \\
\mathrm{M}^{3} \text { list } \\
\text { position }\end{array}$ & $\begin{array}{c}\text { \# } 8 \text { (Max): } \\
\text { Residual } \\
\text { salvo }\end{array}$ & \\
\hline 1 & 0 & 0 & 0 & 34 & 3 & 0 & 92 & 160 & $2,1,3$ \\
\hline $1 \mathrm{~A}$ & 0 & 0 & 10 & 8.7 & 0 & 0 & 92 & 160 & $2,1,3$ \\
\hline $1 \mathrm{~B}$ & 0 & 0 & 10 & 8.7 & 0 & $\underline{3}, 4$ & 92 & 160 & $2,1,3$ \\
\hline 2 & 0 & 0 & 0 & $\underline{27}, 23$ & 2,0 & 0 & 221,184 & 162,157 & $3,69,4$ \\
\hline $2 \mathrm{~A}$ & 0 & 1 & 0 & $4 \overline{4.5}, 42.5$ & 4 & 0 & 196,186 & 141,146 & $4,1,3$ \\
\hline 3 & 0 & $\underline{1}, 0$ & 0 & $1.5,15.5$ & 3 & 0 & 368 & 130,140 & $5,8,14$ \\
\hline 4 & 0 & 1 & 0 & $\underline{16}, 0$ & 4 & 0 & 508,483 & 107,127 & $10,12,52$ \\
\hline 5 & 0 & 0 & 0 & $25 . \overline{4}, 11.4$ & 6,4 & 0 & 599,558 & 252,268 & $10,7,32$ \\
\hline $5 \mathrm{~A}$ & 0 & 0 & 73 & 40 & 4 & 0 & 596 & 227,239 & $10,10,42$ \\
\hline $5 \mathrm{~B}$ & 0 & 1 & 0 & $\underline{35.1}, 20.6$ & 5 & 0 & 629,586 & $\overline{240}, 270$ & $16,54,329$ \\
\hline 6 & 0 & 0 & $\underline{69}, 78$ & $\overline{24}, 13.5$ & 6,5 & 0 & 902,882 & 201,240 & $7,42,172$ \\
\hline 7 & 0 & 0 & 0 & 36 & $\underline{2}, 3$ & 0 & 92 & 160,152 & $2,1,3$ \\
\hline $7 \mathrm{~A}$ & 0 & 0 & 5 & $\underline{34.7}, 28$ & 0 & 0 & 104,92 & 152 & $5,1,2$ \\
\hline $7 \mathrm{~B}$ & 0 & 0 & 10 & 8.7 & 0 & 3 & 92 & 150 & $2,1,2$ \\
\hline 8 & 0 & 0 & 0 & 36 & 0 & 0 & 80 & 162 & $2,1,2$ \\
\hline $8 \mathrm{~A}$ & 0 & 0 & 0 & 36 & 0 & 0 & $\underline{81}, 80$ & 162,153 & $2,1,2$ \\
\hline 9 & 0 & 0 & 0 & 34 & 3 & 0 & 92 & 160 & $3,1,4$ \\
\hline 9A & 0 & 0 & 0 & $\underline{40}, 36$ & 0 & 3,2 & 92 & 160,150 & $3,1,1$ \\
\hline 10 & 0 & 0 & 0 & $\underline{39}, 35$ & 3 & 0 & 157,149 & 147,151 & $3,1,4$ \\
\hline $10 \mathrm{~A}$ & 0 & 0 & 0 & $\underline{37}, 45$ & 3 & 0 & 167,153 & 147,140 & $3,1,3$ \\
\hline 11 & 0 & 0 & 0 & 34 & $\underline{1}, 3$ & 0 & 58,92 & 162,160 & $1,1,5$ \\
\hline 12 & 0 & 0 & 0 & $\underline{43}, 16.5$ & 7 & 0 & 654,665 & 256,271 & $12,46,206$ \\
\hline
\end{tabular}

firing units, or firing units may reload after the strike. On the other hand, salvos within a strike (usually arranged by earliest launch time) are planned so that a follow-on salvo can only make use of the remaining Tomahawk inventory from previous salvos. In this exercise, the fleet assumes a "best-case strike planning:" only primary task-parts are actually fired, whereas redundant allocations become available for subsequent salvos.

Table 3. Result comparison for exercise problems: Heuristic objective value (underlined, if different) and (W)-(H) identical objective values.

\begin{tabular}{|c|c|c|c|c|c|c|c|}
\hline \multirow[b]{2}{*}{$\begin{array}{l}\text { Test } \\
\text { case }\end{array}$} & \multicolumn{6}{|c|}{ Goals } & \multirow[b]{2}{*}{$\begin{array}{l}\text { Solution time } \\
\text { (s): Heuristic, } \\
(\mathrm{W}),(\mathrm{H})\end{array}$} \\
\hline & $\begin{array}{l}\text { \# } 1 \text { (Min): } \\
\text { Unassigned } \\
\text { task parts }\end{array}$ & $\begin{array}{c}\text { \# } 4 \text { (Min): } \\
\text { Deviation } \\
\quad \text { level }\end{array}$ & $\begin{array}{l}\text { \# } 5 \text { (Max): } \\
\text { Spread } \\
\text { primary }\end{array}$ & $\begin{array}{c}\text { \# } 6 \text { (Max): } \\
\text { Spread } \\
\text { back-up }\end{array}$ & $\begin{array}{c}\text { \# } 7 \text { (Min): } \\
\text { M }^{3} \text { List } \\
\text { position }\end{array}$ & $\begin{array}{c}\text { \# } 8 \text { (Max): } \\
\text { Residual } \\
\text { salvo }\end{array}$ & \\
\hline R-S1 & 0 & 6.5 & 3 & $\underline{2}, 4$ & 97 & 148,202 & $1,1,2$ \\
\hline $\mathrm{R}-\mathrm{S} 2$ & 0 & 1.5 & 4 & $\underline{2}, 3$ & 132 & 117,184 & $1,1,2$ \\
\hline R-S3 & 0 & $\underline{49.0}, 43.5$ & 8 & 6 & 481 & 168,257 & $3,2,8$ \\
\hline $\mathrm{R}-\mathrm{S} 4$ & 0 & 34.5 & 6 & 0 & 151 & $\underline{143}, 245$ & $2,1,4$ \\
\hline T-S1-1 & 0 & 40.0 & 4 & 6 & 330 & $\overline{210}, 253$ & $3,3,9$ \\
\hline T-S1-2 & 0 & 4.0 & 4 & $\underline{4}, 6$ & 540,536 & 174,212 & $4,10,30$ \\
\hline T-S1-3 & 0 & 1.7 & 6 & 4 & 747,721 & 116,166 & $3,11,47$ \\
\hline T-S2-4 & 0 & 46.7 & 4 & 6 & 296 & $\underline{233}, 267$ & $4,1,7$ \\
\hline T-S2-5 & 0 & 12.7 & 4 & 6 & $\underline{502}, 491$ & $\overline{198}, 208$ & $7,11,40$ \\
\hline T-S2-6 & 0 & $\underline{7.7}, 2.7$ & 6 & 6 & 736,684 & 132,179 & $8,41,96$ \\
\hline T-S3-7 & 0 & 33.3 & 4 & 6 & 364,360 & 203,252 & $3,2,11$ \\
\hline T-S3-8 & 0 & 40.0 & 6 & $\underline{0}, 3$ & $\overline{584}, 574$ & 151,187 & $6,5,39$ \\
\hline T-S3-9 & 0 & 2.7 & 6 & 0 & 759,718 & 94,123 & $7,29,38$ \\
\hline
\end{tabular}


All (W) and (H) solutions are the same for each goal in all of our exercise problems. Note that goals 2 and 3 are excluded because exercise problems contain neither "penalty" nor "expend" firing units. As opposed to the lab cases where goal 4 was commonly the highest priority objective for which the heuristic failed to produce an optimal solution, we observe that this phenomenon only occurs here in two of the 13 cases. For the remaining cases, it is either goal 6,7 , or 8 which returns suboptimal solutions. The overall solutions (considering all objectives) are of acceptable quality. Regarding each individual goal, for most cases, the heuristic results are reasonably comparable to those produced by the exact models.

However, it is when compared to the "manual" solution produced by the TSC (details not shown) for these exercise cases that we realize the benefit of using optimization-based allocation. Specifically, the TSC fails to meet goal 1 in two of the four Rimpac cases (leaving as many as eleven unassigned task-parts in one case), and in eight of the nine Texas-Thunder scenarios (leaving up to four unassigned task-parts). Compared to all exact solutions (and almost all heuristic solutions) for other goals, the TSC's solutions are always worse. That is, the detriment in goal 1 (or others) is not incurred for the benefit of less important goals either in those solutions. For example, TSC's solution gaps with respect to exact solutions are, on the average, $460 \%, 31 \%, 49 \%, 5 \%$, and $29 \%$ for goals $4,5,6,7$, and 8 , respectively.

\subsection{Additional Exercise-Based Problems}

Three other examples drawn from the exercise problems are considered as separate test cases. These are created by including all salvos within the same Texas-Thunder strike. That is, a new "T-S1" case combines "T-S1-1," "T-S1-2," and "T-S1-3" salvos, a new "T-S2" case comprises "T-S2-4," "TS2-5," and "T-S2-6" salvos, and a new "T-S3" case combines "T-S3-7," "T-S3-8," and "T-S3-9." These cases have, respectively, 168, 156, and 175 tasks, and 232, 229, and 223 taskparts. (That is, these are fleet-wide, complex, very large-scale launch plans.) Because all task-parts are allocated simultaneously for all salvos in a strike, the "best-case strike planning" assumption of the exercise cases is dropped. That is, a missile allocated to a redundant task-part in one salvo cannot be allocated to another task-part for any salvo in the same strike. This is conservative under the assumption that redundant allocations may need to be used if primary missiles fail.

(W) and (H) runs for "T-S1," "T-S2," and "T-S3" take considerably longer than those when salvos are individually considered, requiring several hours of computational time. While in some cases the TSC may have sufficient time to undertake such analysis, we conservatively set up these cases to run in a maximum of 10 minutes or to a relative integrality tolerance of $1 \%$, whichever comes first. For the (W) formulation, this set-up needs no explanation. For the $\left(\mathrm{H}_{k}\right)$ formulation, we allow up to 5 minutes for $k=1$. We then allow up to $50 \%$ of the remaining time for $k=2$, and so forth. The $\left(\mathrm{H}_{k}\right)$ formulation optimizes (or, at least, gives a bound) on each individual objective function after restrictions are imposed by the higher-priority objectives. This allows us to determine not only the quality of the $\left(\mathrm{H}_{k}\right)$ solution but also that of the (W) solution for that goal.

Both exact methods typically exhaust the allotted time although there are exceptions. For example, the (W) problem may terminate early within $1 \%$ from optimal of its own weighted sum objective, which does not imply $1 \%$ optimal for each goal individually considered. On the other hand, the $(\mathrm{H})$ solution may exhaust the maximum time for one of the models $\left(\mathrm{H}_{k}\right)$, but terminate early overall if subsequent models $\left(\mathrm{H}_{k^{\prime}}\right)$, for $k^{\prime}>k$, finish within $1 \%$ of tolerance. The Heuristic algorithm requires between 15 and 42 seconds for these problems.

In all three new cases, solutions for goal 1 are optimal, leaving 4, 3, and 21 nonallocated task-parts, respectively, using either formulation. Notice that this outcome for goal 1 contrasts with that of all other cases in which all taskings are met. For goal 4, the $\left(\mathrm{H}_{4}\right)$ model returns a feasible solution in each case, but the bound is always much lower than such solution's objective value. For example, for "T-S1" the achieved value is 1.7 with a lower bound of 0.0 . Given the goal's nature and the achieved value, the relative error is of little importance in practice: after the allocation, missile inventories left across firing units are very well balanced. The (W) solution for goal 4 is always the same as or worse than that of the $\left(\mathrm{H}_{4}\right)$ model. For all remaining goals (5-8), optimal solutions are achieved by the $\left(\mathrm{H}_{k}\right)$ models (with similar values found by the (W) model), but of course, those solutions could change if a better solution for goal 4 were discovered. The heuristic performance is, again, of high quality, yielding optimal solutions for goal 1 in two of the three cases.

\section{IMPLEMENTATION}

To demonstrate our models and methods, and to gain the trust and acceptance of navy leadership, we had to build a disposable prototypic graphical user interface. However, we knew that if we succeeded in gaining acceptance of our model, our methods would be integrated into a combat system, and our interface would be discarded.

Figure 4 shows one of the planning screens of our prototype system used in tests and initial implementation: the user interface view of Tomahawk task allocations to firing units. At the upper right are navigation buttons to other screens. The next row of buttons permits scenario import, export, display filtering, printing, and emailing of a scenario, while the clear button erases a candidate solution, and the allocate button runs the optimization. For each task, a row shows 


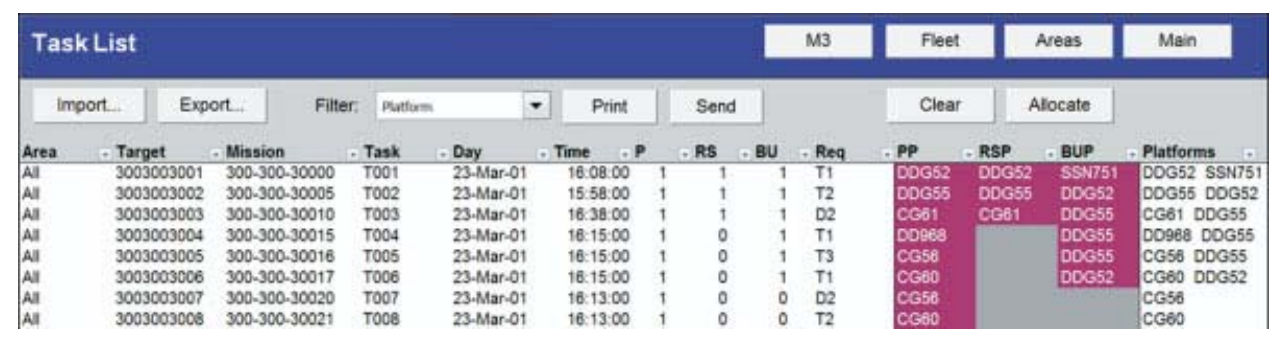

Figure 4. User Interface View of Tomahawk Task Allocations to Firing Units.

the feasible launch area(s), target number, mission id, task, day, and time. The required number of primary, ready-spare, and backup missiles appear in columns labeled P, RS, and BU, respectively. The column entry "Req" specifies the preferred Tomahawk variant missile to be used. The next three, highlighted, columns show the allocation of the required taskparts to firing units. The TSC can optimize a fleet-wide or theater-wide Tomahawk strike using a single button on this dashboard with a laptop computer. (Remark: At the time the prototype was being developed and shown to the navy, refinements to the exact formulation for better solvability were still underway, so only the heuristic algorithm was implemented within the graphical user interface.)

We used this interface to demonstrate our planning model to a number of senior officers, and in presentations to larger groups, such as in meetings of the Military Operations Research Society. Subsequently, the U.S. Navy hired a contractor who efficiently implemented our planner in the operational environment, and thus our prototype user interface was discarded.

\section{CONCLUSION}

A significant part of our research has been devoted to system analyses: capturing all the engineering details governing the capabilities and constraints associated with the allocation of Tomahawk tasks to firing units, merging the engineering with naval tactics, and isolating key issues. We have also developed and defined a standard lexicon with which to discuss these results.

Historically, a TSC primarily performed the allocation of tasks to firing units by hand. Our challenge was to replace the manual procedures with a reliable, carefully documented system to rapidly produce high-quality plans. We have shown by example how to plan optimally for a variety of firing units acting in unison as a combat strike force. We now know how to deliver multiple-ship, multiple-missile strike plans, taking into account a complex variety of constraints and objectives, within seconds.

\section{APPENDIX}

This appendix describes our simplified model formulation for AEGIS ships only.

Naval Research Logistics DOI 10.1002/nav

\section{Indices}

$\begin{array}{ll}s \in S & \begin{array}{l}\text { set of AEGIS ship firing units that can be allocated } \\ \text { task-parts }\end{array} \\ h \in H & \begin{array}{l}\text { set of VLS half-modules on the AEGIS ship firing units } \\ \text { that can be allocated task-parts }\end{array} \\ t \in T & \begin{array}{l}\text { set of strike package tasks that are to be allocated to AEGIS } \\ \text { ship firing units }\end{array} \\ p \in P & \text { set of task-parts (primary, ready-spare, backup) } \\ w \in W & \text { set of Tomahawk weapon types (i.e., XMIDs) loaded } \\ & \text { on the AEGIS ship firing units that can be allocated to } \\ & \text { task-parts }\end{array}$

\section{Index Maps and Subsets}

$$
\begin{aligned}
& T_{s w} \subseteq T \quad \text { subset of tasks that are geofeasible for attack by ship } \\
& s \text { with Tomahawk weapon type } w \\
& T_{s w i} \subseteq T_{s w} \quad \text { subset of tasks in conflict task set } i \text { that are geofeasi- } \\
& \text { ble for attack by ship } s \text { with Tomahawk weapon type } \\
& w \text {, i.e., } T_{s w i}=T_{s w} \cap i \\
& P_{t}^{\mathrm{NS}} \subseteq P \quad \text { subset of nonseparable task-parts for task } t \\
& W_{s h} \subseteq W \quad \text { subset of Tomahawk weapon types that are on ship } s \\
& \text { in half-module } h \\
& W_{s h t} \subseteq W_{s h} \quad \text { subset of Tomahawk weapon types that are on ship } s \\
& \text { in half-module } h \text { that can be used for task } t \\
& H_{s} \subseteq H \quad \text { subset of AEGIS ship VLS half-modules that are on } \\
& \text { ship } s \\
& S_{t} \subseteq S \quad \text { subset of AEGIS ship firing units that are geofeasibly } \\
& S^{E} \subseteq S \quad \text { subset of AEGIS ship firing units that have been } \\
& S^{\mathrm{PR}} \subseteq S \\
& S^{\mathrm{BU}} \subseteq S \\
& S_{t}^{\mathrm{TSC}}, S_{t p}^{\mathrm{TSC}} \subseteq S \\
& \text { designated as "expend" ships } \\
& \text { subset of AEGIS ship firing units to which we wish } \\
& \text { to allocate primary task-parts (see Objective 5) } \\
& \text { subset of AEGIS ship firing units to which we wish } \\
& \text { to allocate backup task-parts (see Objective 6) } \\
& \text { subsets of AEGIS ship firing units designated by } \\
& \text { the TSC as candidates to which to allocate task } t \\
& \text { or task-part } p \text { in task } t \text {, respectively. }
\end{aligned}
$$




\section{Data}

These parameters are needed only for the objective function definitions. $p_{s} \quad$ penalty for using ship $s$

$m_{t w p}^{3} \quad$ penalty for allocating weapon $w$ to part $p$ in task $t$ (based on $\mathrm{M}^{3}$ position of weapon $w$ for task $t$, and the weight of part $p$ to match the $\mathrm{M}^{3}$ list)

$v_{w} \quad$ relative value of weapon $w$ for residual salvo computation

$n_{s h w} \quad$ number of weapons of type $w$ in half-module $h$ on ship $s$

$\omega_{k} \quad$ weight given to goal $k$ when a weighed objective is considered

\section{Primary Decision Variables}

$X_{\text {shwtpm }}$ equals 1 if ship $s$ is assigned to perform the $m$-th missile requirement for task-part $p$ in task $t$ (tentatively using a weapon of type $w$ in half-module $h$ ), and 0 otherwise

$Y_{\text {stpm }} \quad$ equals 1 if ship $s$ is assigned to perform the $m$-th missile requirement for task-part $p$ in task $\mathrm{t}$, and 0 otherwise

$U_{t p m} \quad$ equals 1 if the $m$-th missile requirement for task-part $p$ in task $t$ is unmet, and 0 otherwise

\section{Auxiliary Decision Variables}

These variables are used only to define the objective functions.

$z_{k} \quad$ value of objective function $k$

$V_{s} \quad$ equals 1 if $\operatorname{ship} s$ is used, and 0 otherwise

$\mathrm{RD}_{s} \quad$ difference between the residual number of missiles on ship $s$ and the average residual number of missiles across all "non-expend" ships

$\mathrm{PR}_{s} \quad$ equals 1 if any primary task-part is allocated to ship $s$ (only for $s \in S^{\mathrm{PR}}$ ), and 0 otherwise

$\mathrm{BU}_{s} \quad$ equals 1 if any back-up task-part is allocated to ship $s$ (only for $s \in S^{\mathrm{BU}}$ ), and 0 otherwise

$\mathrm{NS}_{s t p}$ equals 1 if all missile requirements for nonseparable task-part $p$ of task $t$ are assigned to ship $s$, and 0 otherwise

$D_{\text {shw }} \quad$ equals 1 if, based on the information held by the TSC, one weapon of type $w$ would be the most valuable weapon to remain on ship $s$ in half-module $h$ after firing all primary task-part missiles, and 0 otherwise

\section{Objective Functions}

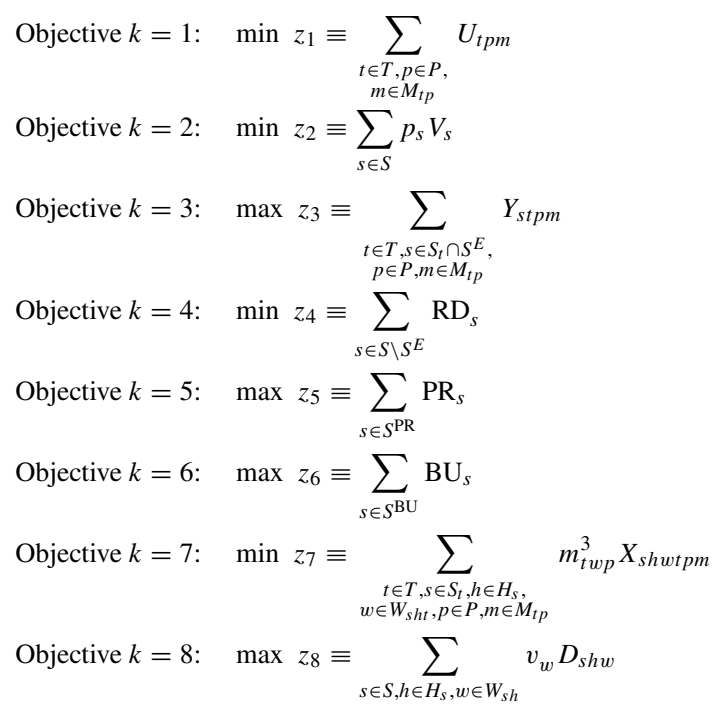

\section{Constraints Enforcing Physical, Policy, and whim of TSC Requirements}

Ensure weapon availability for tasks allocated to half-modules:

$$
\sum_{t \in T_{s w}, p \in P, m \in M_{t p}} X_{s h w t p m} \leq n_{s h w} \quad \forall s \in S, h \in H_{s}, w \in W_{s h}
$$

Establish whether or not a specific firing unit receives a task allocation:

$$
\sum_{h \in H_{s}, w \in W_{\text {sht }}} X_{\text {shwtpm }}=Y_{\text {stpm }} \quad \forall t \in T, s \in S_{t}, p \in P, m \in M_{t p}
$$

Preclude multiple assignments of the same task:

$$
\sum_{s \in S_{t}} Y_{s t p m} \leq 1 \quad \forall t \in T, p \in P, m \in M_{t p}
$$

Preclude partial completions of task parts:

$$
\sum_{s \in S_{t}} Y_{s t,{ }^{\prime}, \text { primary' }^{\prime}, 1^{\prime}}=\sum_{s \in S_{t}} Y_{s t p m} \quad \forall t \in T, p \in P, m \in M_{t p}
$$

Do not assign more than one conflicting task to the same half-module:

$$
\sum_{\substack{w \in W_{s h}, t \in T_{s w i}, p \in P, m \in M_{t p}}} X_{\text {shwtpm }} \leq 1 \quad \forall s \in S, h \in H_{s}, i \in I
$$

Allocate each task, or signal a violation:

$$
\sum_{s \in S_{t}} Y_{s t p m}+U_{t p m}=1 \quad \forall t \in T, p \in P, m \in M_{t p}
$$

Enforce primary and back-up task-part relations:

$$
\begin{aligned}
& Y_{s t,{ }^{\prime} \text { primary' }, m^{\prime}}+Y_{s t,{ }^{\prime} \text { back-up' }{ }^{\prime}, m^{\prime}} \leq 1 \\
& \forall t \in T, s_{t} \in S, m \in M_{t,{ }^{\prime} \text { primary' }}, m^{\prime} \in M_{t,{ }^{\prime} \text { back-up' }}
\end{aligned}
$$

Enforce identical ship allocation for nonseparable task-parts:

$$
\sum_{m \in M_{t p}} Y_{s t p m}=\left|M_{t p}\right| N S_{s t p} \quad \forall t \in T, s \in S_{t}, p \in P_{t}^{N}
$$

Enforce primary and ready-spare task-part relations:

$Y_{s t,{ }^{\prime} \text { primary }{ }^{\prime}, m}=Y_{s t,{ }^{\prime} \text { ready-spare' }, m} \quad \forall t \in T, s \in S_{t}, m \in M_{t,{ }^{\prime} \text { 'ready-spare' }}$

Exclude any allocation the TSC dislikes:

$$
Y_{s t p m}=0 \quad \forall t \in T, p \in P, m \in M_{t p}, s \notin S_{t}^{\mathrm{TSC}} \cap S_{t p}^{\mathrm{TSC}}
$$

Binary decision variables:

$$
\begin{gathered}
X_{\text {shwtpm }} \in\{0,1\} \quad \forall t \in T, s \in S_{t}, h \in H_{s}, w \in W_{s h t}, m \in M_{t p} \\
N S_{s t p} \in\{0,1\} \quad \forall t \in T, s \in S_{t}, p \in P_{t}^{N}
\end{gathered}
$$

Continuous decision variables:

$$
\begin{gathered}
Y_{\text {stpm }} \in[0,1] \quad \forall t \in T, s \in S_{t}, p \in P, m \in M_{p} \\
U_{t p m} \in[0,1] \quad \forall t \in T, p \in P, m \in M_{t p}
\end{gathered}
$$




\section{Constraints Defining Objective Functions}

These relationships do not explicitly constrain the solution and may be handled implicitly in some implementations. They can, of course, be omitted if the corresponding objective is not considered in a particular scenario.

For objective $k=2$ :

$$
\begin{array}{ll}
Y_{s t p m} \leq V_{s}, & \forall t \in T, s \in S_{t}, p \in P, m \in M_{p} \\
V_{s} \in\{0,1\}, & \forall s \in S
\end{array}
$$

For objective $k=4$ :

$$
\mathrm{RD}_{s} \geq 0, \quad \forall s \in S
$$

There are additional details given in Demir [9].

For objectives $k=5$ and $k=6$ :

$$
\begin{aligned}
& \mathrm{PR}_{s} \leq \sum_{\substack{\forall t \mid s \in S_{t}, m \in M_{t, \prime^{\prime} \text { 'rimary' }}}} Y_{s t,^{\prime} \text { primary' }^{\prime}, m}, \quad \forall s \in S^{\mathrm{PR}} \\
& \mathrm{BU}_{s} \leq \sum_{\substack{\forall t \mid s \in S_{t}, m \in M_{t},^{\prime} \text { back-up' }}} Y_{s t t^{\prime} \text { back-up',m }}, \quad \forall s \in S^{\mathrm{BU}} \\
& 0 \leq \mathrm{PR}_{s} \leq 1, \quad \forall s \in S^{\mathrm{PR}} \\
& 0 \leq \mathrm{BU}_{s} \leq 1, \quad \forall s \in S^{\mathrm{BU}}
\end{aligned}
$$

For objective $k=8$ :

$$
\begin{aligned}
& n_{s h w}-\sum_{t \in T_{s w}, m \in M_{t, \text { primary' }^{\prime}}} X_{s h w t, \text { primary' }^{\prime}, m} \geq D_{s h w}, \quad \forall s \in S, h \in H_{s}, w \in W_{s h} \\
& \sum_{w \in W_{s h}} D_{s h w} \leq 1, \quad \forall s \in S, h \in H_{S} \\
& 0 \leq D_{s h w} \leq 1, \quad \forall s \in S, h \in H_{s}, \quad w \in W_{s h}
\end{aligned}
$$

\section{ACKNOWLEDGMENTS}

The authors wish to thank two anonymous reviewers and the Associate Editor for their helpful comments on this article.

Our research and development of decision support prototypes for the fleet required close cooperation between the Naval Postgraduate School and the NSWCDD. The NSW$\mathrm{CDD}$ is the agency responsible for research, development, and test of multiple integrated warfare systems within the navy. We are also grateful for sustaining research support from our Office of Naval Research.

We also acknowledge and thank our succession of M.S. students, Scott Kuykendall, Brian Kirk, Bertram Hodge, Andrew Arnold, Justin Kubu, Paul Wingeart, Ali Demir, and Scott Cullen for their substantive contributions to this project.

Doug "Otter" Otte, Capt-USN, NPS Chair of Warfare Innovation, talked our navy into a publication release. We hope you agree with his argument that this publication would reflect positively on our navy.
Most of all, we credit Rick Rosenthal, who over a decade got us at Naval Postgraduate School involved, one-by-one, with the Tomahawk planning problems, matching us up with our military officer students eager to solve them, and inspiring us all with his deep intellect and good humor. We miss Rick.

\section{REFERENCES}

[1] J. Allewelt, C. Fennemore, M. Makarowski, and G. Shea, Advanced Tomahawk weapons control system predesignation, Naval Surface Warfare Center Dahlgren Division Technical Report 97/18, Dahlgren, VA, 1997.

[2] A. Arnold, A fast heuristic for Tomahawk land-attack predesignation, Master's Thesis in Operations Research, Naval Postgraduate School, Monterey, CA, 2000.

[3] BNET Business Network, Ships/Navy: Surface Combatants, 2003, available at: http://findarticles.com/p/articles/ mi_qa3738/is_200301/ai_n9182566 (accessed on March 30, 2009).

[4] J. Bracken and G.P. McCormick, Selected applications of nonlinear programming, Wiley, New York, 1968, pp. 22-27.

[5] A. Brooke, D. Kendrick, and A. Meeraus, GAMS, a user's guide, GAMS Development Corporation, Washington, DC, 1999.

[6] G.G. Brown, G. Graves, and D. Ronen, Scheduling ocean transportation of crude oil, Management Sci 33 (1987), 335-346.

[7] G.G. Brown, A.M. Newman, R.E. Rosenthal, and A.A. Rowe, "Optimizing Tomahawk strikes," Project Report NPSOR-01-001-PR, Naval Postgraduate School, Monterey, CA, 2001, available at: http://handle.dtic.mil/100.2/ADA386346 (accessed on March 30, 2009).

[8] S. Cullen, Integrating SSGN submarine Tomahawk land attacks into phase-I allocation, Master's Thesis in Operations Research, Naval Postgraduate School, Monterey, CA, 2005.

[9] A. Demir, Tomahawk land attack missile predesignation: optimization revisited, Master's Thesis in Operations Research, Naval Postgraduate School, Monterey, CA, 2004.

[10] C. Dillenberger, L.F. Escudero, A. Wollensak, and W. Zhang, On practical resource allocation for production planning and scheduling with period overlapping setups, Eur J Oper Res 75 (1994), 275-286.

[11] M. Ehrgott, Multicriteria optimization, Lecture notes in economics and mathematical systems, 2nd ed., Springer, BerlinHeidelberg, 2005.

[12] L.F. Escudero and J. Salmeron, On a fix-and-relax framework for a class of project scheduling problems, Ann Oper Res 140 (2005), 163-188.

[13] FAS (Federation of American Scientists), Military analysis network, BGM-109 Tomahawk, 2009, available at: http:// www.fas.org/man/dod-101/sys/smart/bgm-109.htm (accessed on March 30, 2009).

[14] C. Fennemore, K. Fones, M. Kelly, A. Smith, R. Taft, and T. Turner, U.S. SSN preselection for the tactical Tomahawk weapons control system (TTWCS, Version 5), Naval Surface Warfare Center Dahlgren Division Technical Report 99/4, Dahlgren, VA, 2006.

[15] C. Fennemore, C. Johnson, R. Taft, S. Tallant, and W. Tripp, Tomahawk predesignation, Naval Surface Warfare Center Dahlgren Division Technical Report 95/119, Dahlgren, VA, 1995. 
[16] T.P. Harrison and R.E. Rosenthal, Optimizability of utility and value functions, Naval Res Logistics 35 (1998), 411-418.

[17] B. Hodge, A heuristic for Tomahawk land-attack predesignation, Master's Thesis in Operations Research, Naval Postgraduate School, Monterey, CA, 1999.

[18] ILOG, CPLEX 9.0 reference manual, ILOG, SA, France, 2004.

[19] N.K. Jaiswal, Military operations research. Quantitative decision making, Kluwer's International Series, Kluwer Academic Publishers, Norwell, MA, 1997.

[20] Jane's, AEGIS weapon system MK-7, 2007, available at: http://www.janes.com/defence/naval_forces/news/misc/ aegis010425.shtml, (accessed on March 30, 2009).

[21] Jane's, Jane's fighting ships, 2008, available at: jfs.janes.com (accessed on March 30, 2009).

[22] R. Keeney and H. Raiffa, Decision with multiple objectives: Preferences and tradeoffs, Cambridge University Press, Cambridge, 1993.

[23] B. Kirk, Tomahawk strike coordinator predesignation: Optimizing firing platform and weapon allocation, Master's Thesis in Operations Research, Naval Postgraduate School, Monterey, CA, 1999.

[24] J.A. Kubu, Enhancing real-time Tomahawk predesignation to diagnose conflicts, prescribe improvements, and plan multiple strikes, Master's Thesis in Operations Research, Naval Postgraduate School, Monterey, CA, 2001.

[25] S. Kuykendall, Optimizing selection of Tomahawk cruise missiles, Master's Thesis in Operations Research, Naval Postgraduate School, Monterey, CA, 1998.

[26] S. Matlin, A review of the literature on the missile-allocation problem, Oper Res 18 (1970), 334-373.

[27] NSWCDD (Naval Surface Warfare Center, Dahlgren Division), Algorithm description document for the tactical Tomahawk weapon control system, Report JCM-2231/2, Dahlgren, VA, 2003.
[28] R.E. Rosenthal, Principles of multiobjective optimization, Decision Sci 16 (1985), 133-152.

[29] J. Salmeron, Heuristic algorithm for TLAM predesignation project, Project deliverable, available from author at Operations Research Department, Naval Postgraduate School, Monterey, CA, 2002.

[30] R.M. Soland, Multicriteria optimization: A general characterization of efficient solutions, Decision Sci 10 (1979), 26-39.

[31] R.E. Steuer, Multiple criteria optimization: Theory, computation and application, Wiley, New York, NY, 1986.

[32] Sun Microsystems Inc, Sun microsystems documentation, 2009, available at: http://docs.sun.com/ (accessed on March 30, 2009).

[33] United States Navy (USN), DDG 1000. Navy designates next-generation zumwalt destroyer, 2008, available at: http:// peoships.crane.navy.mil/ddg1000/default.htm (accessed on March 30, 2009).

[34] M. Urioste, Tomahawk cruise missile control: Providing the right tools to the warfighter, Crosstalk - The Journal of Defense Software Engineering, 2004, available at: http://www.stsc.hill.af.mil/crosstalk/2004/09/0409Urioste. html (accessed on March 30, 2009).

[35] D.J. White, A bibliography on the application of mathematical programming multiple-objective methods, J Oper Res Soc 41 (1990), 669-691.

[36] P.H. Wingeart, An improvement heuristic for Tomahawk landattack predesignation, enhanced to accommodate manual planning, and validated with fleet exercise data, Master's Thesis in Operations Research, Naval Postgraduate School, Monterey, CA, 2001.

[37] M. Zeleny, Multiple criteria decision making, McGraw Hill, New-York, 1982. 